Published in final edited form as:

Nat Methods. ; 8(11): 957-962. doi:10.1038/nmeth.1712.

\title{
Rapid and robust generation of functional oligodendrocyte progenitor cells from epiblast stem cells
}

\author{
Fadi J. Najm ${ }^{1}$, Anita Zaremba ${ }^{2}$, Andrew V. Caprariello ${ }^{2}$, Shreya Nayak ${ }^{1}$, Eric C. Freundt ${ }^{3}$, \\ Peter C. Scacheri ${ }^{1}$, Robert H. Miller ${ }^{2}$, and Paul J. Tesar ${ }^{1,2,4,{ }^{*}}$ \\ ${ }^{1}$ Department of Genetics, Case Western Reserve University School of Medicine, Cleveland, Ohio, \\ USA. \\ ${ }^{2}$ Department of Neurosciences, Case Western Reserve University School of Medicine, Cleveland, \\ Ohio, USA. \\ ${ }^{3}$ Department of Microbiology and Immunology, Stanford University School of Medicine, Stanford, \\ California, USA. \\ ${ }^{4}$ New York Stem Cell Foundation, Case Western Reserve University School of Medicine, \\ Cleveland, Ohio, USA.
}

\section{Abstract}

\begin{abstract}
Myelin-related disorders such as multiple sclerosis and leukodystrophies, where restoration of oligodendrocyte function would provide an effective treatment, are poised to benefit greatly from stem cell biology. Progress in myelin repair has been constrained by difficulties in generating pure populations of oligodendrocyte progenitor cells (OPCs) in sufficient quantities. Pluripotent stem cells theoretically provide an unlimited source of OPCs but current differentiation strategies are poorly reproducible and generate heterogenous populations of cells. Here we provide a platform for the directed differentiation of pluripotent mouse epiblast stem cells (EpiSCs) through a defined series of developmental transitions into a pure population of highly expandable OPCs in ten days. These OPCs robustly differentiate into myelinating oligodendrocytes in vitro and in vivo. Our results demonstrate that mouse pluripotent stem cells provide a pure population of myelinogenic oligodendrocytes and offer a tractable platform for defining the molecular regulation of oligodendrocyte development and drug screening.
\end{abstract}

\footnotetext{
Users may view, print, copy, download and text and data- mine the content in such documents, for the purposes of academic research, subject always to the full Conditions of use: http://www.nature.com/authors/editorial_policies/license.html\#terms

*Contact: Paul J. Tesar, PhD, Department of Genetics, Case Western Reserve University, 10900 Euclid Ave., Cleveland, Ohio 44106, USA, Phone: (216) 368-6225, Fax: (216) 368-0491, paul.tesar@case.edu.

AUTHOR CONTRIBUTIONS

F.J.N. and P.J.T. derived the EpiSC-OPC lines and carried out in vitro experiments; A.V.C., A.Z., F.J.N., and P.J.T. performed in vivo experiments; A.Z., F.J.N. R.H.M., and P.J.T. performed slice culture experiments; E.C.F. carried out the co-culture experiments; F.J.N., S.N., and P.J.T. performed drug screening experiments; F.J.N., P.C.S., and P.J.T. generated and analyzed gene expression data; F.J.N., R.H.M., and P.J.T. analyzed all of the data and wrote the paper.
} 


\section{INTRODUCTION}

Myelin is an essential component of the vertebrate nervous system and serves as an electrical insulator for the effective conduction of action potentials along nerve axons. The incapacitating effects of myelin defects impact millions of people worldwide and are readily apparent in acquired demyelinating conditions such as multiple sclerosis and cerebral palsy as well as congenital dysmyelinating disorders such as Pelizaeus-Merzbacher disease and vanishing white matter disease. Curative therapies currently remain unfeasible owing to the inability to promote remyelination in response to myelin loss. Remyelination would necessitate either the pharmacologic restoration of the myelinating capacity of endogenous cells or transplantation of exogenous, functional oligodendrocyte progenitor cells (OPCs) ${ }^{1}$. OPCs are an important cell type in the central nervous system for myelin maintenance and repair as they are uniquely capable of responding to extrinsic cues and generating myelinogenic cells ${ }^{2}$. Interestingly, even mature oligodendrocytes do not appear to maintain an intrinsic ability to respond to new myelination cues and therefore bona fide OPCs are a sought after target for myelin repair strategies.

Previous studies have created excitement for myelin repair by demonstrating that oligodendrocytes may be derived from neural stem cells and pluripotent stem cells. These approaches, however, have yet to closely match the pace of normal development or yield a high percentage of oligodendrocytes. Current strategies often generate a mixture of uncharacterized, tri-potent neural precursors, not OPCs, and rely heavily on immunopanning, antibiotic resistance, or cell sorting techniques to improve population characteristics $3,4,5,6$. Thus far the field has been lacking a controlled and scalable production of pure, committed OPCs.

Our study aimed to establish precise methodologies to control the production of pure, functional OPCs from pluripotent stem cells. We show that mouse pluripotent stem cells can be guided through defined developmental transitions to rapidly produce a pure population of expandable mouse OPCs. These pluripotent stem cell-derived OPCs function to generate myelinogenic oligodendrocytes and serve as a tractable platform for the identification of small molecules that promote myelination. Future translation of our results to human pluripotent stem cells offers promise for cell-based myelin repair strategies.

\section{RESULTS}

\section{Region-specific neuroepithelium in five days}

The allocation of pluripotent cells in the embryo to their somatic and germ cell fates is orchestrated by a complex array of signals emanating from distinct regions ${ }^{7}$. We postulated that precise control of these signals would allow for the routine and specific generation of sufficient quantities of OPCs from pluripotent stem cells (see Supplementary Fig. 1 for overview). Our studies focused on mouse epiblast stem cells (EpiSCs) due to their in vitro tractability and because they share defining features and developmental state with human embryonic stem cells (ESCs) and human induced pluripotent stem cells (iPSCs). We have previously shown that EpiSCs provide an ideal system to define the molecular regulation of cell fate transitions during early development ${ }^{8}$. EpiSCs are isolated from either pre- or early 
post-implantation mouse embryos and represent the most proximal cell type to all the somatic and germ cell lineages in the developing embryo; the epiblast ${ }^{8,9,10}$.

To specify EpiSCs into the neuroectodermal lineage, we modulated both the activin/Nodal and bone morphogenetic protein (BMP) signaling pathways with small molecule inhibitors (see Methods). Previous work in Xenopus, mouse, and pluripotent stem cells has demonstrated that TGF- $\beta$ family signaling, through intracellular SMAD effectors, plays a significant role in neural induction $8,11,12,13$. Employing these developmental cues, we treated EpiSCs with SB431542, an inhibitor of Alk4, 5, \& 7 (activin/Nodal signaling), dorsomorphin or LDN-193189, inhibitors of Alk2, 3, \& 6 (BMP signaling), and noggin, a BMP antagonist. In response, the EpiSCs rapidly down-regulated the expression of pluripotency genes such as Oct3/4 (Fig. 1b,g and Supplementary Fig. 2d), up-regulated neuroectodermal genes such as Pax6 and Soxl (Fig. 1d,g), and underwent morphological changes to form radially organized neural rosettes (Fig.1a,c and Supplementary Fig. 2a,b). This differentiation strategy was extremely robust and resulted in $>99 \%$ of EpiSC colonies forming Pax6 positive (Pax6+) and Sox1+ (co-expressing) rosettes (Supplementary Fig. 2c).

Our next step was to further pattern the 'naïve' EpiSC-derived neural rosettes in a regionspecific manner. In the developing neural tube, specific cellular precursor domains are established by local signals from the surrounding tissues ${ }^{14}$. In the developing spinal cord OPCs first emerge from the ventral ventricular zone of the neural tube in response to sonic hedgehog (SHH) and other signals from the notochord and floor plate ${ }^{15,16,17}$. Therefore, we treated our day four EpiSC-derived neural rosettes for one day with specific concentrations of retinoic acid (RA) and SHH in the continued presence of noggin to pattern them in a region specific way (see Methods) ${ }^{18}$. This treatment resulted in the up-regulation of OPC relevant transcription factors Olig2 and Nkx2.2 (Fig. 1e). Strikingly, the expression pattern of these factors in the rosettes mimicked the non-overlapping expression in the ventral ventricular zone of the developing mouse neural tube ${ }^{18,19}$ (Fig. 1f). Additionally, EpiSCderived patterned rosettes expressed Hox genes 1-8 thus confirming their spinal cord identity along the rostrocaudal axis ${ }^{20}$ (Supplementary Fig. 3 ). These results demonstrate that the provision of guiding developmental cues leads to the proper specification and patterning of pluripotent cells into region-specific cells of the developing spinal cord in five days.

\section{Expandable OPCs from patterned neuroectoderm}

We next sought to determine whether we could further differentiate the patterned EpiSCderived neural rosettes into a continuously dividing OPC population. After their specification in vivo, OPCs proliferate in response to PDGF and FGF signals ${ }^{21,22}$ and migrate extensively to populate the central nervous system (CNS). To recapitulate these events, we dissociated our patterned EpiSC-derived neural rosettes and plated them onto a laminin substrate (this primary passaging event was denoted as 'passage 0 ') in the presence of PDGF-AA, FGF2, and SHH. Upon passage our EpiSC-derived neural rosettes immediately gave rise to both $\beta$ III-tubulin+ neurons and presumptive OPCs which showed expression of Olig2 or Nkx2.2 (Supplementary Fig. 4a,b). These results recapitulate in vivo cell specification events at the ventral ventricular zone of the developing spinal cord that are known to give rise to both neurons and $\mathrm{OPCs}^{23}$. In our cultures the neurons did not persist 
beyond the first three days of culture (Supplementary Fig. 4c). However, the presumptive OPCs developed strong, co-expression of Olig2 and Nkx2.2 and rapidly proliferated in the presence of FGF2, PDGF, and SHH to produce a confluent and nearly homogeneous population of cells within five days (ten days from initial differentiation of the EpiSCs) (Fig. 2a-c and Supplementary Fig. 4d-f). These EpiSC-derived OPCs exhibited a typical bipolar morphology (Fig. 2a) and expressed transcription factors and cell surface markers such as Olig1, Olig2, Nkx2.2, Sox10, PDGFRa, A2B5, and NG2 (Cspg4) consistent with their in vivo counterparts ${ }^{24}$ (Fig. 2b,c,f). The EpiSC-derived OPCs were synchronous and highly pure as $\sim 90 \%$ were shown to co-express the OPC surface markers NG2 and PDGFRa by flow cytometry without selection or sorting (Fig. 2e). Additionally, these EpiSC-derived OPCs could be expanded for at least eight passages yielding previously unobtainable numbers $\left(>1 \times 10^{12}\right)$ of pure OPCs (Fig. 2 d). To demonstrate the robustness of our protocol we simultaneously differentiated four independently derived EpiSC cell lines (including lines from mice of different genders, strains, and developmental stage). All four cell lines differentiated efficiently into OPCs without any cell line specific modifications to the protocol (Supplementary Fig. 5). These results demonstrate that highly expandable, defined populations of OPCs can be rapidly and robustly generated from pluripotent stem cells.

\section{OPC differentiation and functional myelination}

To determine the differentiation capacity of our EpiSC-derived OPCs we treated them with thyroid hormone (T3), which is known to be important both in vitro and in vivo in regulating the transition of OPCs into oligodendrocytes, in the absence of both FGF2 and PDGF-AA ${ }^{25}$. These conditions caused the EpiSC-derived OPCs to stop proliferating and differentiate exclusively into oligodendrocytes over a 2-4 day time course (Fig. 3a-c and Supplementary Video 1). Undifferentiated OPCs were completely negative for the oligodendrocyte cell surface marker $\mathrm{O} 4$, but by day two of differentiation greater than $64 \%$ of the cells were strongly O4+ with multiprocesses and the rest remained as Olig2+ OPCs (Fig. 5a; cells manually counted from random fields of independent lines, $\mathrm{n}>480$ ). By day three, these $\mathrm{O} 4+$ oligodendrocytes up-regulated all of the classical and defining markers of bona fide oligodendrocytes such as myelin basic protein (Mbp), proteolipid protein 1 (Plp1), myelin associated glycoprotein $(\mathrm{Mag})$, and myelin oligodendrocyte glycoprotein $(\mathrm{Mog})^{24}$ (Fig. $3 b, c)$. The differentiation was highly specific as we never observed GFAP+ astrocytes or $\beta I I I-t u b u l i n+$ neurons. By day four, the overwhelming majority of EpiSC-derived OPCs had become oligodendrocytes but cell death and rare proliferation events make exact quantification challenging without large-scale time-lapse lineage analysis. To further test the robustness of our protocol, we differentiated OPCs derived from four independent EpiSC lines into oligodendrocytes and noted no apparent differences in the efficiency or timing of differentiation (Supplementary Fig. 5). Freezing/thawing and extensive expansion of the OPCs also did not alter their properties or ability to differentiate as all passages tested showed highly correlated global gene expression patterns and generated oligodendrocytes with similar timing and efficiency (Supplementary Fig. 6a-d).

To examine the functional properties of EpiSC-derived OPCs, their myelinogenic potential was evaluated by in vitro co-culture with neurons as well as injection into the brains of congenitally hypomyelinated mice both in organotypic slice culture and in vivo. For in vitro 
co-culture studies, EpiSC-derived OPCs were plated at low density onto cultures of mouse cortical neurons and allowed to differentiate ${ }^{2}$. After six days, the EpiSC-derived OPCs had differentiated into MBP+ cells. Importantly, much of the MBP+ staining tracked with $\beta I I I-$ tubulin+ axons which is suggestive of their myelinogenic capacity (Fig. 3d). Interestingly, EpiSC-derived OPCs previously exposed to $\mathrm{T} 3 \mathrm{did}$ not produce $\mathrm{MBP}+$ segments which tracked with $\beta I I I-t u b u l i n+$ cells suggesting temporal restriction of myelinogenic potential. To further assess the functionality of our EpiSC-derived OPCs, we developed a tractable organotypic slice culture assay to evaluate their myelinogenic potential. Injection of EpiSCderived OPCs into coronal, forebrain slices of early postnatal shiverer $\left(\mathrm{Mbp}^{\text {shi/shi }}\right)$ pups (which lack $M b p$ and compact myelin) resulted in significant numbers of MBP+ segments and compact myelin after ten days (Fig. 4a-c). Transplanted EpiSC-derived OPCs specifically differentiated into oligodendrocytes and did not form neurons in the shiverer brain slices (Supplementary Fig. 7a,b). The ability of EpiSC-derived OPCs to myelinate shiverer host axons in slice culture was also assessed using both low and high passage cells with no differences evident (Fig. 4b).

To assess the myelinogenic capacity of EpiSC-OPCs in vivo, we delivered $2.5 \times 10^{5}$ cells into the future corpus callosum of newborn, immunocompetent shiverer $\left(\mathrm{Mbp}^{\text {shi/shi }}\right)$ pups. Animals were sacrificed between 3-7 weeks and assayed for the presence of myelinated fibers in the brain. Numerous patches of MBP+ myelin sheaths were found in animals transplanted with EpiSC-derived OPCs but not in untransplanted controls (Fig. 4d). Additionally, EpiSC-derived OPCs appeared to migrate extensively in the host CNS as myelination was seen at sites distant from the injection such as the contralateral striatum (Fig. 4d). No teratomas or aberrant cellular growths were evident in any of the mice transplanted with EpiSC-derived OPCs at the time points evaluated. Taken together, our results demonstrate that EpiSC-derived OPCs function to produce compact myelin and provide a tractable source of cells to optimize cell-based transplantation strategies for myelin repair.

\section{A scalable screening platform for OPC differentiation}

We next explored the ability of extrinsic factors to modulate the differentiation of EpiSCderived OPCs. Since this system allows for the scalable production of OPCs from pluripotent cells, it provides a platform to screen for molecules that influence the transition of OPCs into oligodendrocytes. This is especially pertinent to disorders such as multiple sclerosis where NG2+ OPCs are present in or close to demyelinated lesions but generally fail to remyelinate demyelinated axons ${ }^{26}$. As a simple proof-of-principle for using our system to screen for compounds, we exposed EpiSC-derived OPCs to three different treatment regimens involving modulation of signaling pathways - Notch, Wnt/ $\beta$-catenin, and BMP - previously implicated in oligodendrocyte development or differentiation. Treatment of EpiSC-derived OPCs for two days with T3 differentiation media in the presence of the Notch ligand Jagged1 (Jag1) did not impact the rate or number of O4+ oligodendrocytes (Fig. 5a,b). A similar protocol was utilized to test the role of GSK3 $\beta$, a negative regulator of Wnt/ $\beta$-catenin signaling, by treating EpiSC-derived OPCs with the GSK3 $\beta$ inhibitor CHIR99021. This treatment resulted in a concentration dependent inhibition of oligodendrocyte differentiation whereby cells remained as Olig2+ OPCs and failed to 
progress to $\mathrm{O} 4+$ oligodendrocytes (Fig. $5 \mathrm{c}, \mathrm{e}$ ). These results suggest that canonical $\mathrm{Wnt} / \beta$ catenin signaling, activated by inhibition of GSK3 $\beta$, may positively regulate the OPC state and functions to block the transition to oligodendrocytes ${ }^{27}$. The final treatment involved exposure of EpiSC-derived OPCs to signaling cascades known to respecify OPCs in vitro into an alternate glial fate, astrocytes ${ }^{28,29}$. Treatment of EpiSC-derived OPCs with BMP4 and leukemia inhibitory factor (LIF) resulted in the majority of cells undergoing morphological and gene expression changes including the upregulation of GFAP indicative of respecification into astrocytes (Fig. 5d). These results demonstrate that our scalable mouse pluripotent stem cell-based system provides a powerful way to screen for modulators of oligodendrocyte development and myelination.

\section{DISCUSSION}

Strategies to restore function in patients afflicted with myelin-based disorders rely on either the modulation of endogenous OPCs or transplantation of exogenous myelinogenic cells. The ability to screen for relevant compounds or generate a homogenous population of transplantable cells requires a tractable system to generate sufficient quantities of functional OPCs for study. Thus far it has not been feasible to obtain the requisite number of OPCs in high purity regardless of the methodology employed. Here we demonstrate a robust differentiation platform whereby mouse pluripotent stem cells are guided through a defined series of developmental transitions to recapitulate the complex signaling environments present in the developing embryo. Our approach allowed for the rapid production of pure, highly expandable populations of mouse OPCs, capable of differentiation into large numbers of functional oligodendrocytes with great efficiency. This developmental system will afford a detailed understanding of the gene expression changes and signaling pathway requirements throughout the entire oligodendrocyte lineage (see Supplementary Fig. 8 and Supplementary Table 1). This data may offer insight into the causative cell and molecular defects that function in congenital disorders impacting the oligodendrocyte lineage.

Our system also provides a robust platform to perform high-throughput screens for drugs that modulate the functional differentiation of mouse OPCs. Our small-scale screen identified that inhibition of GSK3 $\beta$, a negative regulator of the canonical Wnt/ $\beta$-catenin signaling pathway, blocked the transition of mouse OPCs into functional oligodendrocytes. Previous work has also shown that the Wnt signaling pathway is aberrantly active in demyelinating lesions of human patients with multiple sclerosis ${ }^{27}$. Together, these results suggest that our mouse EpiSC-based system may prove useful to screen for compounds that effectively target endogenous OPCs in patients.

Remyelinating strategies may also require the provision of exogenous myelinogenic cells. Transplantation of fetal human glial progenitor cells has been shown to lead to recovery in a lethally hypomyelinated mouse model ${ }^{30}$. While clearly establishing proof-of-principle for translation to human patients, cells from aborted human fetuses not only face ethical and immunological challenges but scalability to a large clinical quantity may not be realistic. Our results in the mouse show that pluripotent cells can be rapidly differentiated into OPCs capable of functional myelination. Future studies will take advantage of the purity and scalability of this system to optimize transplantation strategies (injection site, timing, and 
dosing) for functional recovery from dysmyelinating conditions. Since EpiSCs share defining features and differentiation responses with human ESCs and iPSCs, the potential extension of our OPC differentiation regimen to human pluripotent cells offers excitement for the treatment of human myelin-related disorders in the future.

\section{METHODS}

\section{Differentiation of EpiSCs to neuroectoderm}

All cells were cultured at $37^{\circ} \mathrm{C}$ and $5 \% \mathrm{CO}_{2}$ unless otherwise noted. Individual EpiSC lines were isolated from mice of strains 129SvEv (EpiSC5 and EpiSC7), 129S1/SvImJ (129O1), and 129SvEvxICR (EpiSC9) and maintained in vitro as previously described in EpiSC base medium supplemented with $10 \mathrm{ng} \mathrm{ml}^{-1}$ FGF2 (R\&D Systems, 233-FB) $)^{8,10,31}$.

Differentiation of EpiSCs to patterned, neural rosettes was a five day procedure with complete media changes every day.

EpiSC base medium consisted of Knockout DMEM (Invitrogen) supplemented with 20\% Knockout Serum Replacement (KSR; Invitrogen), 2mM Glutamax (Invitrogen), 1× nonessential amino acids (Invitrogen), and $0.1 \mathrm{mM}$ 2-mercaptoethanol (Sigma).

Neural base medium consisted of DMEM/F12 (Invitrogen; 11320) supplemented with 1× N2 (R\&D Systems), 1× B-27 without vitamin A (Invitrogen) and $2 \mathrm{mM}$ Glutamax (Invitrogen).

Day 0: EpiSCs were plated under standard passaging conditions in EpiSC base medium supplemented with $100 \mathrm{ng} \mathrm{ml}^{-1}$ Noggin (R\&D Systems), $20 \mu$ M SB431542 (Sigma; maintained as a $20 \mathrm{mM}$ stock solution in DMSO), and $2 \mu \mathrm{M}$ dorsomorphin (EMD; supplied as a $10 \mathrm{mM}$ stock solution in DMSO). $0.1 \mu \mathrm{M}$ LDN-193189 (Stemgent; maintained as a 1 $\mathrm{mM}$ stock solution according to the manufacturer's instructions) was used in place of dorsomorphin for some experiments. Day 1: Cultures were fed with a 1:1 mixture of EpiSC base medium and neural base medium supplemented with $100 \mathrm{ng} \mathrm{ml}^{-1}$ Noggin, $20 \mu \mathrm{M}$ SB431542, and $2 \mu \mathrm{M}$ dorsomorphin. Day 2: Cultures were fed with neural base medium supplemented with $100 \mathrm{ng} \mathrm{ml}^{-1}$ Noggin, $20 \mu \mathrm{M} \mathrm{SB} 431542$, and $2 \mu \mathrm{M}$ dorsomorphin. Day 3: Cultures were fed with neural base medium supplemented with $100 \mathrm{ng} \mathrm{ml}^{-1}$ Noggin. Day 4: Cultures were fed with neural base medium supplemented with $100 \mathrm{ng} \mathrm{ml}^{-1}$ Noggin, $10 \mu \mathrm{M}$ RA (Sigma; maintained as a $20 \mathrm{mM}$ stock solution in DMSO), and $200 \mathrm{ng} \mathrm{m}^{-1}$ Sonic Hedgehog (SHH) (R\&D Systems; C24II).

\section{Differentiation of EpiSC-derived patterned, neuroectoderm to OPCs}

Day five patterned rosettes were released from the culture dish using $1.5 \mathrm{mg} / \mathrm{ml}$ collagenase IV (Invitrogen) and dissociated to a single cell suspension using TrypLE Select (Invitrogen). Cells were counted and plated at $4 \times 10^{4}$ cells cm${ }^{-2}$ on Nunclon- $\Delta$ plates coated with $0.1 \mathrm{mg}$ $\mathrm{ml}^{-1}$ poly-L-ornithine (Sigma) followed by $10 \mu \mathrm{g} \mathrm{ml}^{-1}$ laminin (Sigma; L2020). Cells were grown in OPC medium consisting of neural base medium supplemented with $20 \mathrm{ng} \mathrm{ml}^{-1}$ FGF2, $20 \mathrm{ng} \mathrm{ml}^{-1}$ PDGF-AA (R\&D Systems), and $200 \mathrm{ng} \mathrm{ml}^{-1}$ SHH and fed every other day for five days. At this point cultures consisted of a highly pure population of proliferating OPCs. 


\section{OPC culture}

Cultures of EpiSC-derived OPCs were maintained and expanded in neural base medium supplemented with $20 \mathrm{ng} \mathrm{ml}^{-1}$ FGF2, $20 \mathrm{ng} \mathrm{ml}^{-1}$ PDGF-AA, and $200 \mathrm{ng} \mathrm{ml}^{-1} \mathrm{SHH}$ or 20 $n g \mathrm{ml}^{-1}$ PDGF-AA, $200 \mathrm{ng} \mathrm{ml}^{-1} \mathrm{SHH}, 100 \mathrm{ng} \mathrm{ml}^{-1}$ Noggin, $10 \mu \mathrm{M}$ dibutyryl cyclic-AMP sodium salt (Sigma), $100 \mathrm{ng} \mathrm{ml}^{-1}$ IGF-1 (R\&D Systems), and $10 \mathrm{ng} \mathrm{ml}^{-1}$ NT3 (R\&D Systems) and fed every other day. OPCs were grown on Nunclon- $\Delta$ plates coated with polyL-ornithine and laminin. Cells were passaged every 3-5 days with TrypLE Select and typically seeded at $2 \times 10^{4}$ cells $\mathrm{cm}^{-2}$. OPCs could be readily frozen/thawed and were cryopreserved in DMEM supplemented with $10 \%$ fetal bovine serum (FBS; Invitrogen) and $10 \%$ DMSO (Sigma).

For the cumulative OPC experiment (Fig. $2 \mathrm{~d}$ ), at 'passage 0 ' $4 \times 10^{4}$ cells $\mathrm{cm}^{-2}$ were seeded. Subsequently, cells were passaged at $80-90 \%$ confluence and seeded at $2 \times 10^{4}$ cells cm$^{-2}$. Total cell number at each passage was counted with a haemocytometer. Rates of growth were determined at each passage and extended to the entire population of cells to yield a cumulative count.

\section{Differentiation of EpiSC-derived OPCs}

For differentiation of OPCs into oligodendrocytes, cells were plated at $2.2 \times 10^{4} \mathrm{cells} \mathrm{cm}^{-2}$ and induced with neural base medium supplemented with $0.4 \mathrm{ng} \mathrm{ml}^{-1} \mathrm{~T} 3$ (Sigma), $200 \mathrm{ng}$ $\mathrm{ml}^{-1} \mathrm{SHH}, 100 \mathrm{ng} \mathrm{ml}^{-1}$ Noggin, $10 \mu \mathrm{M}$ dibutyryl cyclic-AMP sodium salt, $100 \mathrm{ng} \mathrm{ml}^{-1}$ IGF-1, and $10 \mathrm{ng} \mathrm{ml}^{-1} \mathrm{NT}$. Attempts to modulate the outcome of this differentiation paradigm included treatments with Jag1 (R\&D Systems), CHIR99021 (Stemgent), LIF (Millipore), and/or BMP4 (R\&D Systems).

\section{Time lapse imaging of EpiSC-derived OPC differentiation}

For live cell imaging experiments, EpiSC-derived OPCs were plated onto poly-L-ornithine and laminin coated glass bottom microwell dishes (MatTek, P35G-1.5-14-C). Cells were seeded at a density of $3.1 \times 10^{4}$ cells $\mathrm{cm}^{-2}$ in differentiation media (T3, SHH, Noggin, cAMP, IGF1, and NT3). After allowing the cells to adhere for three hours, images were collected every ten minutes for up to 72 hours with a Hamamatsu Orca CCD camera (Hamamatsu Photonics) on an inverted microscope (Leica DMI6000B) outfitted with a precision scanning stage (Marzhauser) within a live cell incubation chamber and cover (Pecon) at $37^{\circ} \mathrm{C}$ and $5 \% \mathrm{CO}_{2}$. Adaptive Focus Control (AFC) was used to maintain multiposition focus stability over time. Movies were generated using Image Pro Plus and Adobe Premiere Pro CS5.

\section{Immunostaining}

In vitro cultured cells were prepared for immunostaining by fixation in $4 \%$ paraformaldehyde (Electron Microscopy Sciences) for 15 minutes and subsequent permeabilization for ten minutes with $0.2 \%$ Triton- $X$ in PBS. Cells were then blocked for non-specific binding with $10 \%$ normal goat (Abcam) or 10\% normal donkey serum (Abcam) in PBS for 1-2 hours at room temperature. Primary antibodies were diluted in blocking solution and incubated on the samples either overnight at $4{ }^{\circ} \mathrm{C}$ or for one hour at room temperature. Samples were rinsed with PBS and incubated with the appropriate 
fluorescently labeled Alexa secondary antibodies (Invitrogen; $4 \mu \mathrm{g} \mathrm{ml}^{-1}$ ) for one hour at room temperature. For visualization of nuclei, samples were incubated with $1 \mu \mathrm{g} \mathrm{m}{ }^{-1}$ DAPI (Sigma) in PBS for five minutes.

Live cell staining was used for the cell surface marker O4. Live cells were blocked with $10 \%$ normal goat serum and treated with $\mathrm{O} 4$ antibody (R. Miller lab) for 20 minutes at $37^{\circ} \mathrm{C}$. Cells were gently rinsed three times with warm neural base media and fixed in $4 \%$ paraformaldehyde. Samples were rinsed with PBS and incubated with a fluorescently labeled Alexa secondary antibody (Invitrogen; $4 \mu \mathrm{g} \mathrm{ml}^{-1}$ ) for one hour at room temperature. Cells were then permeabilized and stained with DAPI to visualize nuclei.

Primary antibodies used were: Oct3/4 (Santa Cruz, sc-5279; $0.4 \mu \mathrm{g} \mathrm{ml}^{-1}$ ), Sox1 (R\&D Systems, AF3369; $1 \mu \mathrm{g} \mathrm{ml}^{-1}$ ), Pax6 (Covance, PRB-278P; $0.67 \mu \mathrm{g} \mathrm{ml}^{-1}$ ), Olig2 (Millipore, AB9610; 1:1000), Nkx2.2 (DSHB, 74.5A5; $4.4 \mu \mathrm{g} \mathrm{ml}^{-1}$ ), Sox10 (R\&D Systems, AF2864; 2 $\mu \mathrm{g} \mathrm{ml}^{-1}$ ), O4 (R. Miller Lab; 1:10), GFAP (DAKO, Z0334; $0.58 \mu \mathrm{g} \mathrm{ml}^{-1}$ ), $\beta$ III-tubulin (Covance, Tuj1; $0.2 \mu \mathrm{g} \mathrm{ml}^{-1}$ ), and MBP (Covance, SMI-99P; $2 \mu \mathrm{g} \mathrm{ml}^{-1}$ or Abcam, ab7349; 1:25). The Nkx2.2 (74.5A5) antibody developed by T. Jessell \& S. Brenner-Morton was obtained from the Developmental Studies Hybridoma Bank developed under the auspices of the NICHD and maintained by The University of Iowa, Department of Biology, Iowa City, IA 52242.

For embryo tissue, embryonic day 11.5 (E11.5) embryos were fixed in 4\% paraformaldehyde and cryosectioned. After antigen retrieval using sodium citrate buffer (10 $\mathrm{mM}$ sodium citrate, $0.05 \%$ Tween $20, \mathrm{pH}=6.0$ ), sections were blocked in $10 \%$ donkey serum with $0.2 \%$ Triton- $X$ for two hours. Sections were then stained in blocking solution using Olig2 (Millipore, AB9610; 1:200) and Nkx2.2 (DSHB, 74.5A5; $8.8 \mu \mathrm{g} \mathrm{ml}^{-1}$ ) antibodies overnight at $4^{\circ} \mathrm{C}$. Alexa secondary antibodies (Invitrogen; $4 \mu \mathrm{g} \mathrm{m}{ }^{-1}$ ) were used for detection and nuclei were visualized with DAPI.

For flow cytometry of PDGFRa and NG2, EpiSC-derived OPCs were harvested from culture and blocked in $10 \%$ normal donkey serum for 30 minutes. Cells were then stained with APC-conjugated PDGFRa (eBioscience, APA5; $4 \mu \mathrm{g} \mathrm{ml}^{-1}$ ) and unconjugated rabbit polyclonal NG2 (Millipore, AB5320; $1 \mu \mathrm{g} \mathrm{m}^{-1}$ ) antibodies for 30 minutes followed by incubation with Alexa secondary antibody (Invitrogen; $4 \mu \mathrm{g} \mathrm{m}^{-1}$ ) for 20 minutes. Isotype control antibodies were used as a staining control and to set gates [APC-conjugated rat IgG (eBioscience; $4 \mu \mathrm{g} \mathrm{ml}^{-1}$ ) and normal rabbit $\operatorname{IgG}\left(\right.$ Santa Cruz; $1 \mu \mathrm{g} \mathrm{ml}^{-1}$ ) with Alexa secondary antibody (Invitrogen; $4 \mu \mathrm{g} \mathrm{ml}^{-1}$ )]. Cells were analyzed on a BD FACSAria and plots were generated with WinList 3D 7.0 software. Quadrant gates were set with isotype controls at less than $0.1 \%$ double positive cells.

\section{Co-culture myelination analysis}

Primary neurons were obtained from the cortex of E17 mice. Following dissection, the cortex was incubated in $0.125 \%$ trypsin in Earle's balanced salt solution (EBSS) for eight minutes at $37^{\circ} \mathrm{C}$ and resuspended in $10 \mathrm{ml}$ of DMEM containing $10 \%$ FBS. The cortex was centrifuged at $2500 \mathrm{rpm}$ for two minutes and resuspended in $1 \mathrm{ml}$ of Neural Basal Media (NBM) containing 2\% B27 (Invitrogen) and $0.25 \%$ Glutamax (Invitrogen) $)^{2}$. The cortex was 
then triturated through three glass pipettes of decreasing diameter, centrifuged, resuspended in supplemented NBM, and filtered through a $40 \mu \mathrm{m}$ cell strainer (BD Biosciences). Cells were plated on chamber coverslips that had been coated with poly-D-lysine and laminin and maintained at $37^{\circ} \mathrm{C}, 10 \% \mathrm{CO}_{2}$ for one week. EpiSC-derived OPCs were suspended in NDGrowth media ${ }^{2}$ and added to the neuron cultures. Cells were processed for immunofluorescence after six days of co-culture and analyzed using MBP (Abcam) and BIIItubulin (Tuj1; Neuromics) antibodies. Alexa secondary antibodies $\left(2 \mu \mathrm{g} \mathrm{ml}^{-1}\right)$ were used for detection and nuclei were visualized with DAPI.

\section{in vivo myelination analysis}

All experiments with animals were approved by the Institutional Animal Care and Use Committee of CWRU. Early post-natal (P1-P3) shiverer $\left(\mathrm{Mbp}^{\text {shi/shi }}\right)$ mice served as a host for the transplantation of EpiSC-derived OPC. Pups were anesthetized with isofluorane and $2.5 \times 10^{5}$ cells suspended in $1.5 \mu$ of neural base medium were injected unilaterally to target the future corpus callosum at a rate of $0.5 \mu \mathrm{min}^{-1}$. Injections were performed with a Hamilton syringe through the skull right of midline AP $+0.5 \mathrm{~mm}, \mathrm{ML}+0.5 \mathrm{~mm}$, and a depth of $2 \mathrm{~mm}$. Mice injected with EpiSC-derived OPCs as well as controls were sacrificed at various time points to analyze myelination. Mice were deeply anaesthetized with rodent cocktail (Ketamine, Xylazine and Acepromazine), perfused transcardially with roomtemperature $0.9 \%$ saline, and then perfused with ice-cold $4 \%$ paraformaldehyde. The brain was dissected and post-fixed for two hours in $4 \%$ paraformaldehyde then cryoprotected with sucrose. The cortex was frozen in OCT medium on dry ice and $20 \mu \mathrm{m}$ sections were cut on a Microm 525 cryostat. The sections were air-dried and then frozen.

For fluorescent MBP staining, slides were thawed and allowed to dry, then rehydrated in PBS. Slides were treated with ice-cold 95\% methanol and 5\% acetic acid for seven minutes, rinsed in PBS, and blocked in 10\% goat serum for one hour at room temperature. Slides were then stained overnight for MBP (Covance; $2 \mu \mathrm{g} \mathrm{ml}^{-1}$ ). Alexa secondary antibodies (Invitrogen; $2 \mu \mathrm{g} \mathrm{ml}^{-1}$ ) were used for detection and nuclei were visualized with DAPI. Stained sections were mounted using Vectashield and imaged using a Zeiss LSM 510 META laser scanning confocal microscope. All images presented are maximum intensity projections of a $\mathrm{Z}$ series consisting of $1.8 \mu \mathrm{m}$ optical slices collected every $0.9 \mu \mathrm{m}$ (optimal interval setting determined by LSM 510 software).

\section{Organotypic slice culture myelination analysis}

The forebrain of early post-natal (P2-4) shiverer or wildtype mice was dissected and $300 \mu \mathrm{m}$ coronal slices were made on a Leica Vibratome. Slices were cultured as previously described $^{32}$ in a DMEM/BME base with $15 \%$ Horse serum, modified N2, and PDGF-AA for three days. $2 \times 10^{5}$ EpiSC-derived OPCs were manually injected with a pulled glass pipette into the slices and grown for an additional ten days in culture. Some OPC cultures were first lentivirally labeled with GFP (see Supplementary Fig. 7a). Slices were fixed in 4\% paraformaldehyde, treated with ice-cold $95 \%$ methanol and 5\% acetic acid, and assayed for MBP expression (Covance; Jackson Labs, Biotin-anti-mouse IgG; Vector Labs, ABC; Sigma, DAB). For lineage tracing experiments, slices were assayed for NeuN expression (Millipore, ABN78) and GFP (Invitrogen, 3E6). To analyze the myelin ultrastructure, fixed 
and MBP stained slices were post-fixed (4\% paraformaldehyde and $2 \%$ glutaraldehyde in 0.1 M Cacodylate buffer, $\mathrm{pH} 7.4$ ), incubated in $1 \%$ osmium tetroxide, and stained en bloc in uranyl acetate. They were dehydrated and embedded in Poly/Bed 812 epoxy. Thick $(1 \mu \mathrm{m})$ sections were cut and stained with toluidine blue. Thin $(90 \mathrm{~nm})$ sections were cut either en face or transversely, collected on $300 \mu \mathrm{m}$ nickel grids, stained with toluidine blue, and carbon coated for electron microscopy (EM). Toluidine blue stained thick sections were imaged on a Leica DM5500B microscope at 100x and toluidine blue thin sections were imaged at $80 \mathrm{kV}$ on a JEOL JEM-1200-EX electron microscope. Staining of sections for MBP prior to EM allowed for efficient targeting of the regions to be analyzed but this methodology did subject the tissue to some degradation largely due to the acid methanol permeabilization step.

\section{Genotyping}

Shiverer mice were genotyped with a multiplex PCR protocol devised by the Mouse Genetics Core at Washington University (see Supplementary Table 2 for primer sequences). For PCR, Klentaq LA DNA Polymerase (Clontech 639108) was used along with 1.3M Betaine. Cycling conditions for PCR were $93^{\circ} \mathrm{C}$ for one minute, 30 cycles of $93^{\circ} \mathrm{C}$ for 20 seconds followed by $68^{\circ} \mathrm{C}$ for three minutes, held at $4^{\circ} \mathrm{C}$.

\section{Global gene expression}

Cells were lysed in $1 \mathrm{ml}$ TRIzol (Invitrogen) and stored at $-80^{\circ} \mathrm{C}$ until ready for use. Chloroform separation was enhanced with Phase-Lock Gel Tubes (5 Prime). The aqueous phase was collected and the RNA isolation completed with the RNeasy Plus Kit (Qiagen) according to the manufacturer's protocol. Biotinylated cRNA was prepared from $150 \mathrm{ng}$ of total RNA using the Affymetrix GeneChip Whole Transcript Sense Target Labeling Assay according to the manufacturer's instructions. Labeled cRNA (10 $\mu \mathrm{g})$ was hybridized for 17 hours at $45^{\circ} \mathrm{C}$ on Affymetrix Mouse Gene 1.0 ST arrays, washed, and stained in the Affymetrix Fluidics Station 450. Sample labeling and hybridization to Affymetrix Mouse Gene 1.0 ST arrays were carried out in the Gene Expression and Genotyping Core Facility of the Case Comprehensive Cancer Center. Cel files were generated with the Affymetrix GeneChip Command Console 2.0 and the data were normalized with the RMA method using the default settings in Expression Console Software (Affymetrix). All data are available on the NCBI Gene Expression Omnibus website through GEO Series accession GSE31562. For clustering analysis in Supplementary Fig. 8, Shannon entropy was used to rank genes specific to each cell type ${ }^{33}$. Values for genes where $\mathrm{Q}<1.65 * \mathrm{H}$ were $\mathrm{Z}$ transformed ${ }^{34}$ and samples were clustered with Gene Cluster 3.0 software using centroid linkage and displayed with Java Treeview software. This analysis generated 502, 491, 181, and 449 unique annotated genes specific to EpiSCs, day 5 neural rosettes, OPCs, and oligodendrocytes respectively (see Supplementary Table 1 for lists). The heatmap in Supplementary Fig. 3 was generated in R using the heatmap. 2 function of the gplots package. For comparison of low and high passage OPCs and oligodendrocytes (p3 and p11) in Supplementary Fig. 6c, a correlation dendrogram was generated in R from Z-transformed whole genome expression data (genes not expressed in any of the samples were excluded from analysis; total genes utilized $=13,183$ ). 


\title{
Supplementary Material
}

Refer to Web version on PubMed Central for supplementary material.

\section{ACKNOWLEDGEMENTS}

\begin{abstract}
This research was supported by funding from NIH (MH087877;NS30800), Case Western Reserve University School of Medicine, the Myelin Repair Foundation, the New York Stem Cell Foundation, and the Cytometry \& Imaging Microscopy, the Gene Expression and Genotyping, and the Radiation Resources Core facilities of the Case Comprehensive Cancer Center (P30 CA43703). S.N. was supported by the ENGAGE program of the Center for Stem Cell and Regenerative Medicine. P.J.T. is a Robertson Investigator of the New York Stem Cell Foundation. We are grateful to L. Cooperman, M. Hitomi, E. Hitomi, C. Batt, M. Pendergast, K. Wyatt as well as members of the P. Scacheri and R. Atit laboratories for technical assistance and provision of reagents. Additionally we would like to thank I. Tsung for artwork contained in Supplementary Figure 8, and J. Drazba, J. Peterson, and K. Ryan for assistance with live cell imaging.
\end{abstract}

\section{References}

1. Goldman SA, Schanz S, Windrem MS. Stem cell-based strategies for treating pediatric disorders of myelin. Hum Mol Genet. 2008; 17(R1):R76-R83. [PubMed: 18632701]

2. Watkins TA, Emery B, Mulinyawe S, Barres BA. Distinct stages of myelination regulated by gamma-secretase and astrocytes in a rapidly myelinating cns coculture system. Neuron. 2008; 60(4): 555-569. [PubMed: 19038214]

3. Billon N, Jolicoeur C, Ying QL, Smith A, Raff M. Normal timing of oligodendrocyte development from genetically engineered, lineage-selectable mouse es cells. J Cell Sci. 2002; 115(Pt 18):36573665. [PubMed: 12186951]

4. Brustle O, Jones KN, Learish RD, Karram K, Choudhary K, et al. Embryonic stem cell-derived glial precursors: A source of myelinating transplants. Science. 1999; 285(5428):754-756. [PubMed: 10427001]

5. Hu BY, Du ZW, Zhang SC. Differentiation of human oligodendrocytes from pluripotent stem cells. Nat Protoc. 2009; 4(11):1614-1622. [PubMed: 19834476]

6. Nistor GI, Totoiu MO, Haque N, Carpenter MK, Keirstead HS. Human embryonic stem cells differentiate into oligodendrocytes in high purity and myelinate after spinal cord transplantation. Glia. 2005; 49(3):385-396. [PubMed: 15538751]

7. Tam PP, Loebel DA. Gene function in mouse embryogenesis: Get set for gastrulation. Nat Rev Genet. 2007; 8(5):368-381. [PubMed: 17387317]

8. Tesar PJ, Chenoweth JG, Brook FA, Davies TJ, Evans EP, et al. New cell lines from mouse epiblast share defining features with human embryonic stem cells. Nature. 2007; 448(7150):196-199. [PubMed: 17597760]

9. Brons IG, Smithers LE, Trotter MW, Rugg-Gunn P, Sun B, et al. Derivation of pluripotent epiblast stem cells from mammalian embryos. Nature. 2007; 448(7150):191-195. [PubMed: 17597762]

10. Najm FJ, Chenoweth JG, Anderson PD, Nadeau JH, Redline RW, et al. Isolation of epiblast stem cells from preimplantation mouse embryos. Cell Stem Cell. 2011; 8(3):318-325. [PubMed: 21362571]

11. Chambers SM, Fasano CA, Papapetrou EP, Tomishima M, Sadelain M, et al. Highly efficient neural conversion of human es and ips cells by dual inhibition of smad signaling. Nat Biotechnol. 2009; 27(3):275-280. [PubMed: 19252484]

12. Hemmati-Brivanlou A, Melton DA. Inhibition of activin receptor signaling promotes neuralization in xenopus. Cell. 1994; 77(2):273-281. [PubMed: 8168134]

13. Camus A, Perea-Gomez A, Moreau A, Collignon J. Absence of nodal signaling promotes precocious neural differentiation in the mouse embryo. Dev Biol. 2006; 295(2):743-755. [PubMed: 16678814]

14. Jessell TM. Neuronal specification in the spinal cord: Inductive signals and transcriptional codes. Nat Rev Genet. 2000; 1(1):20-29. [PubMed: 11262869] 
15. Orentas DM, Miller RH. The origin of spinal cord oligodendrocytes is dependent on local influences from the notochord. Dev Biol. 1996; 177(1):43-53. [PubMed: 8660875]

16. Trousse F, Giess MC, Soula C, Ghandour S, Duprat AM, et al. Notochord and floor plate stimulate oligodendrocyte differentiation in cultures of the chick dorsal neural tube. J Neurosci Res. 1995; 41(4):552-560. [PubMed: 7473887]

17. Noll E, Miller RH. Oligodendrocyte precursors originate at the ventral ventricular zone dorsal to the ventral midline region in the embryonic rat spinal cord. Development. 1993; 118(2):563-573. [PubMed: 8223279]

18. Wichterle H, Lieberam I, Porter JA, Jessell TM. Directed differentiation of embryonic stem cells into motor neurons. Cell. 2002; 110(3):385-397. [PubMed: 12176325]

19. Sun T, Echelard Y, Lu R, Yuk DI, Kaing S, et al. Olig bhlh proteins interact with homeodomain proteins to regulate cell fate acquisition in progenitors of the ventral neural tube. Curr Biol. 2001; 11(18):1413-1420. [PubMed: 11566099]

20. Krumlauf R, Marshall H, Studer M, Nonchev S, Sham MH, et al. Hox homeobox genes and regionalisation of the nervous system. J Neurobiol. 1993; 24(10):1328-1340. [PubMed: 7901322]

21. Bogler O, Wren D, Barnett SC, Land H, Noble M. Cooperation between two growth factors promotes extended self-renewal and inhibits differentiation of oligodendrocyte-type-2 astrocyte (o-2a) progenitor cells. Proc Natl Acad Sci U S A. 1990; 87(16):6368-6372. [PubMed: 2201028]

22. Noble M, Murray K, Stroobant P, Waterfield MD, Riddle P. Platelet-derived growth factor promotes division and motility and inhibits premature differentiation of the oligodendrocyte/type-2 astrocyte progenitor cell. Nature. 1988; 333(6173):560-562. [PubMed: 3287176]

23. Richardson WD, Pringle NP, Yu WP, Hall AC. Origins of spinal cord oligodendrocytes: Possible developmental and evolutionary relationships with motor neurons. Dev Neurosci. 1997; 19(1):5868. [PubMed: 9078434]

24. Cahoy JD, Emery B, Kaushal A, Foo LC, Zamanian JL, et al. A transcriptome database for astrocytes, neurons, and oligodendrocytes: A new resource for understanding brain development and function. J Neurosci. 2008; 28(1):264-278. [PubMed: 18171944]

25. Barres BA, Lazar MA, Raff MC. A novel role for thyroid hormone, glucocorticoids and retinoic acid in timing oligodendrocyte development. Development. 1994; 120(5):1097-1108. [PubMed: 8026323]

26. Chang A, Nishiyama A, Peterson J, Prineas J, Trapp BD. Ng2-positive oligodendrocyte progenitor cells in adult human brain and multiple sclerosis lesions. J Neurosci. 2000; 20(17):6404-6412. [PubMed: 10964946]

27. Fancy SP, Baranzini SE, Zhao C, Yuk DI, Irvine KA, et al. Dysregulation of the wnt pathway inhibits timely myelination and remyelination in the mammalian cns. Genes Dev. 2009; 23(13): 1571-1585. [PubMed: 19515974]

28. Hughes SM, Lillien LE, Raff MC, Rohrer H, Sendtner M. Ciliary neurotrophic factor induces type-2 astrocyte differentiation in culture. Nature. 1988; 335(6185):70-73. [PubMed: 3412463]

29. Mabie PC, Mehler MF, Marmur R, Papavasiliou A, Song Q, et al. Bone morphogenetic proteins induce astroglial differentiation of oligodendroglial-astroglial progenitor cells. J Neurosci. 1997; 17(11):4112-4120. [PubMed: 9151728]

30. Windrem MS, Schanz SJ, Guo M, Tian GF, Washco V, et al. Neonatal chimerization with human glial progenitor cells can both remyelinate and rescue the otherwise lethally hypomyelinated shiverer mouse. Cell Stem Cell. 2008; 2(6):553-565. [PubMed: 18522848]

31. Chenoweth JG, Tesar PJ. Isolation and maintenance of mouse epiblast stem cells. Methods Mol Biol. 2010; 636:25-44. [PubMed: 20336514]

32. Mi S, Miller RH, Tang W, Lee X, Hu B, et al. Promotion of central nervous system remyelination by induced differentiation of oligodendrocyte precursor cells. Ann Neurol. 2009; 65(3):304-315. [PubMed: 19334062]

33. Schug J, Schuller WP, Kappen C, Salbaum JM, Bucan M, et al. Promoter features related to tissue specificity as measured by shannon entropy. Genome Biol. 2005; 6(4):R33. [PubMed: 15833120]

34. Cheadle C, Vawter MP, Freed WJ, Becker KG. Analysis of microarray data using z score transformation. J Mol Diagn. 2003; 5(2):73-81. [PubMed: 12707371] 
a

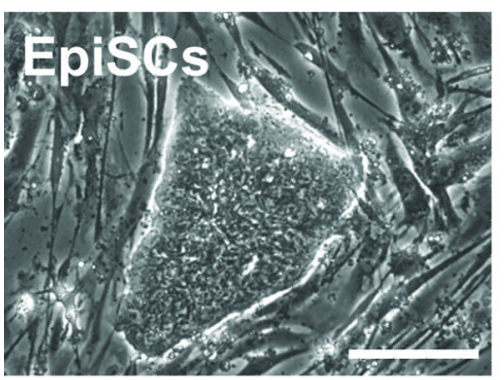

b

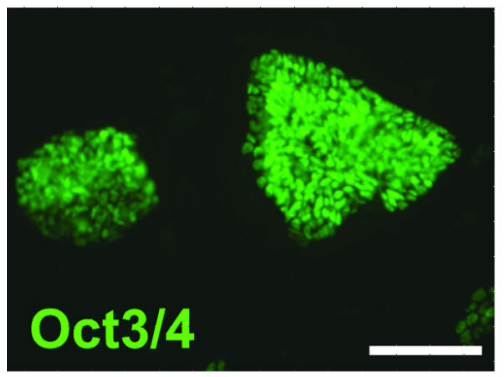

C

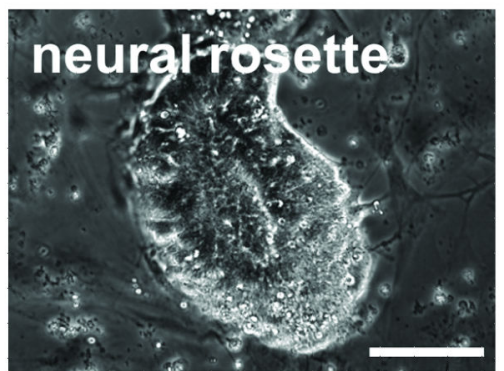

d

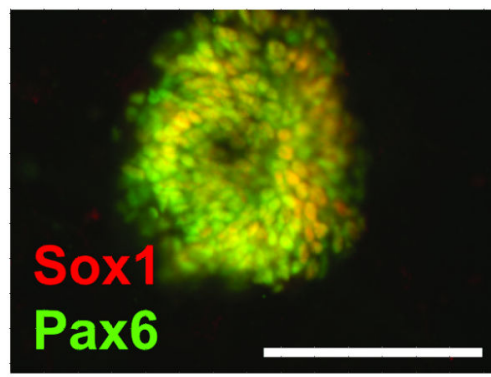

e

\section{day 5 rosette}

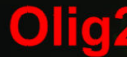

Nkx2.2

f
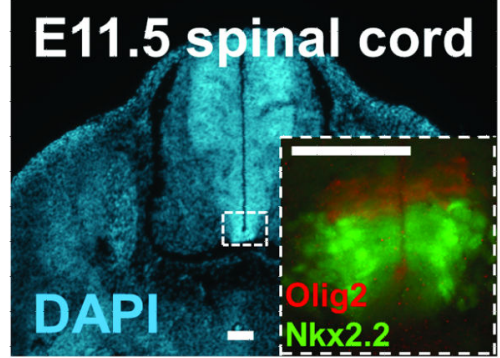

g

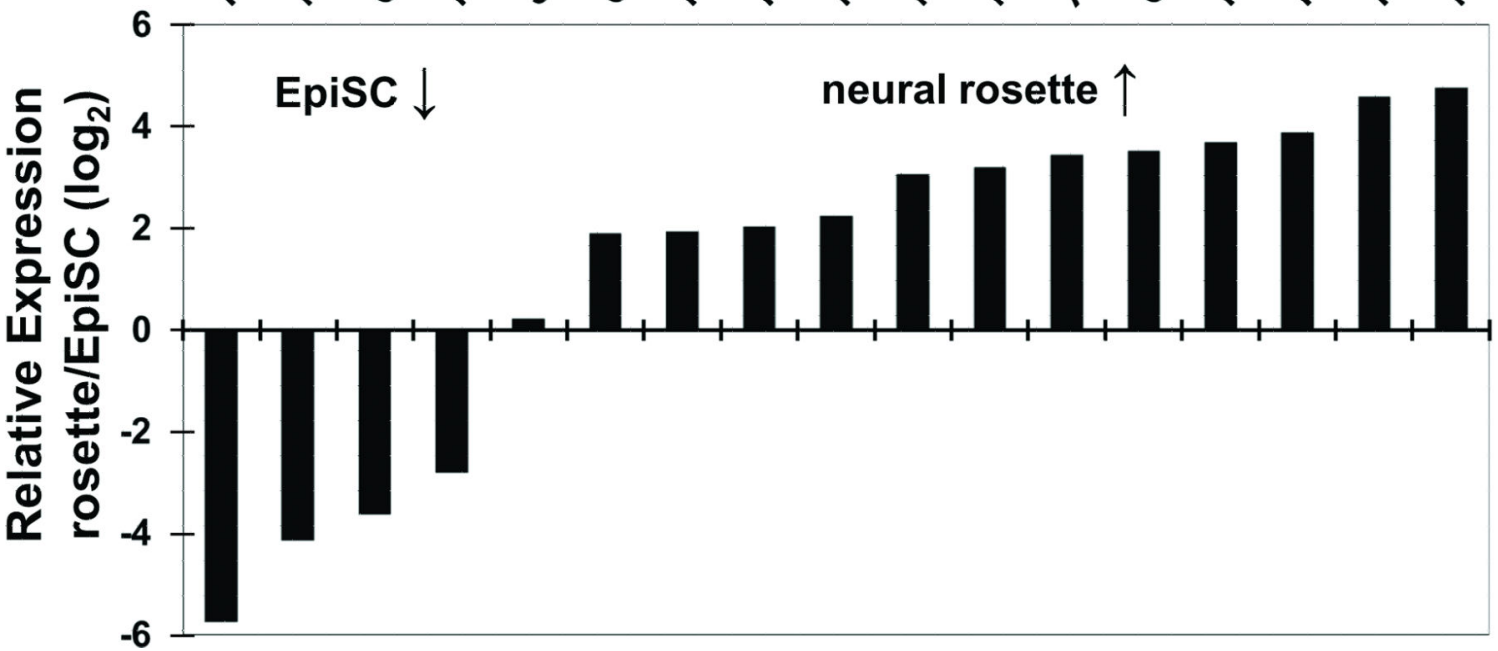

Figure 1. Efficient differentiation of epiblast stem cells into region-specific neuroepithelial cells in five days

Treatment of (a) pluripotent EpiSCs which express (b) Oct3/4 (green) with factors to block both BMP and activin/Nodal signaling results in their progression to (c) neural rosettes expressing (d) Sox1 (red) and Pax6 (green). The five day treatment regimen results in patterned neural rosettes expressing the (e) region-specific transcription factors Olig2 (red) and Nkx2.2 (green) which are (f) normally expressed in the ventral, ventricular zone of the mouse embryonic spinal cord. (g) Genome wide transcriptional profiling during the 
transition of EpiSCs to patterned neural rosettes confirmed a rapid down-regulation of pluripotency genes and up-regulation of genes specific to the developing neuroectoderm. Scale bars, $100 \mu \mathrm{m}(\mathbf{a}-\mathbf{e})$ and $50 \mu \mathrm{m}(\mathbf{f})$. 
a

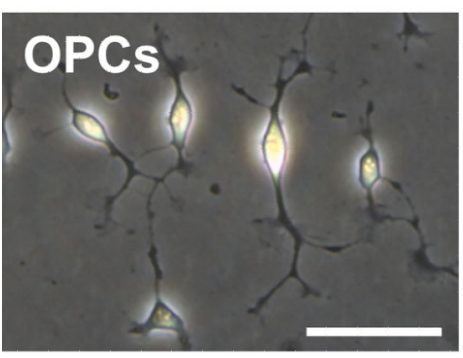

d

\#

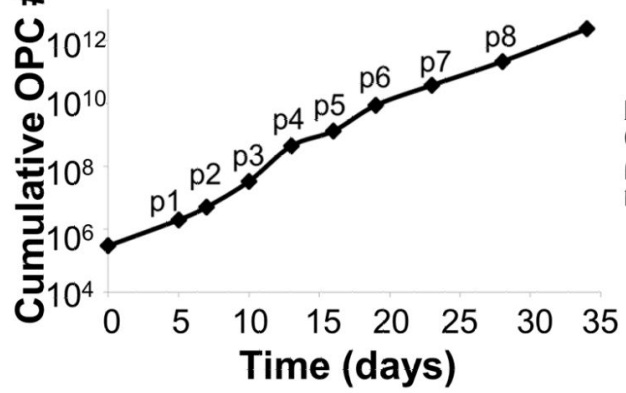

b

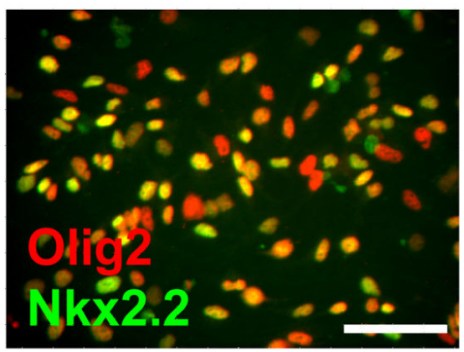

C

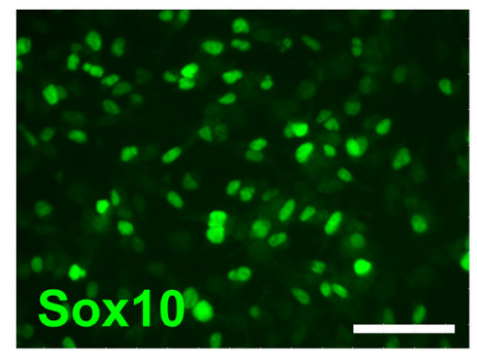

e

Low passage OPCs High passage OPCs
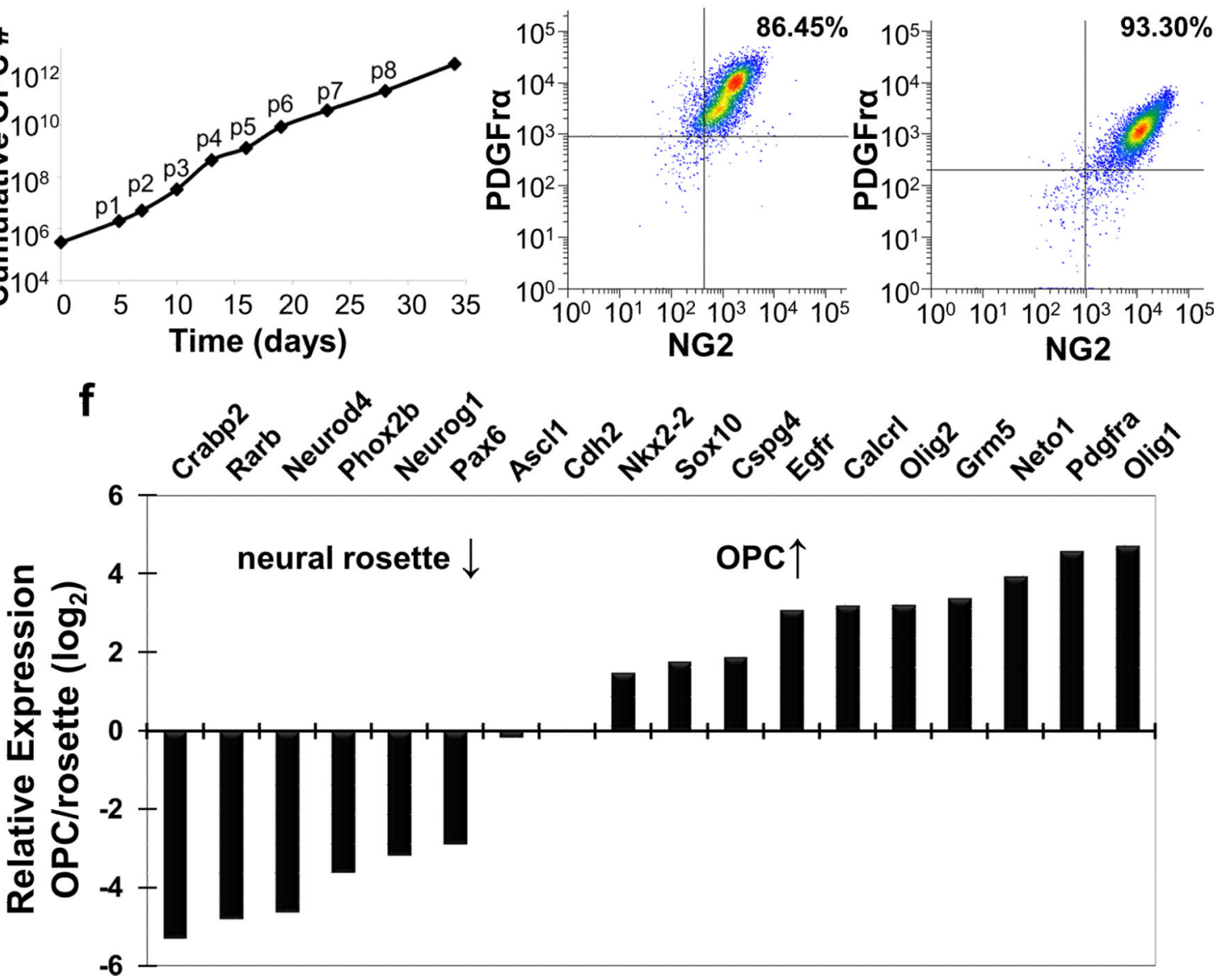

Figure 2. Highly expandable OPCs derived from patterned EpiSC-derived neuroectoderm Patterned neural rosettes derived from EpiSCs were dissociated and grown on a laminin substrate in the presence of FGF2, PDGF-AA, and SHH resulting in the formation of OPCs.

(a) Phase contrast image of EpiSC-derived OPCs showing characteristic bi-polar morphology. Immunostaining revealed that the OPCs were highly pure as (b) $89.9 \%$ coexpressed transcription factors Olig2 (red) and Nkx2.2 (green) and (c) $89.2 \%$ expressed Sox 10 (green) without sorting or selection ( $\mathrm{n}>600$ cells from random fields were manually counted for each marker). (d) EpiSC-derived OPCs could be extensively expanded at least 8 
passages. Shown is a graph depicting cumulative cell number counts over multiple passages (passage denoted 'p'). (e) Flow cytometric analyses revealed that both low passage (p2) and high passage (p12) EpiSC-derived OPCs robustly co-expressed OPC surface markers NG2 and PDGFRa. (f) Genome wide transcriptional profiling during the transition of EpiSCderived neural rosettes to OPCs revealed a rapid down-regulation of rosette-specific genes and up-regulation of genes specific to OPCs. Scale bars, $50 \mu \mathrm{m}$. 

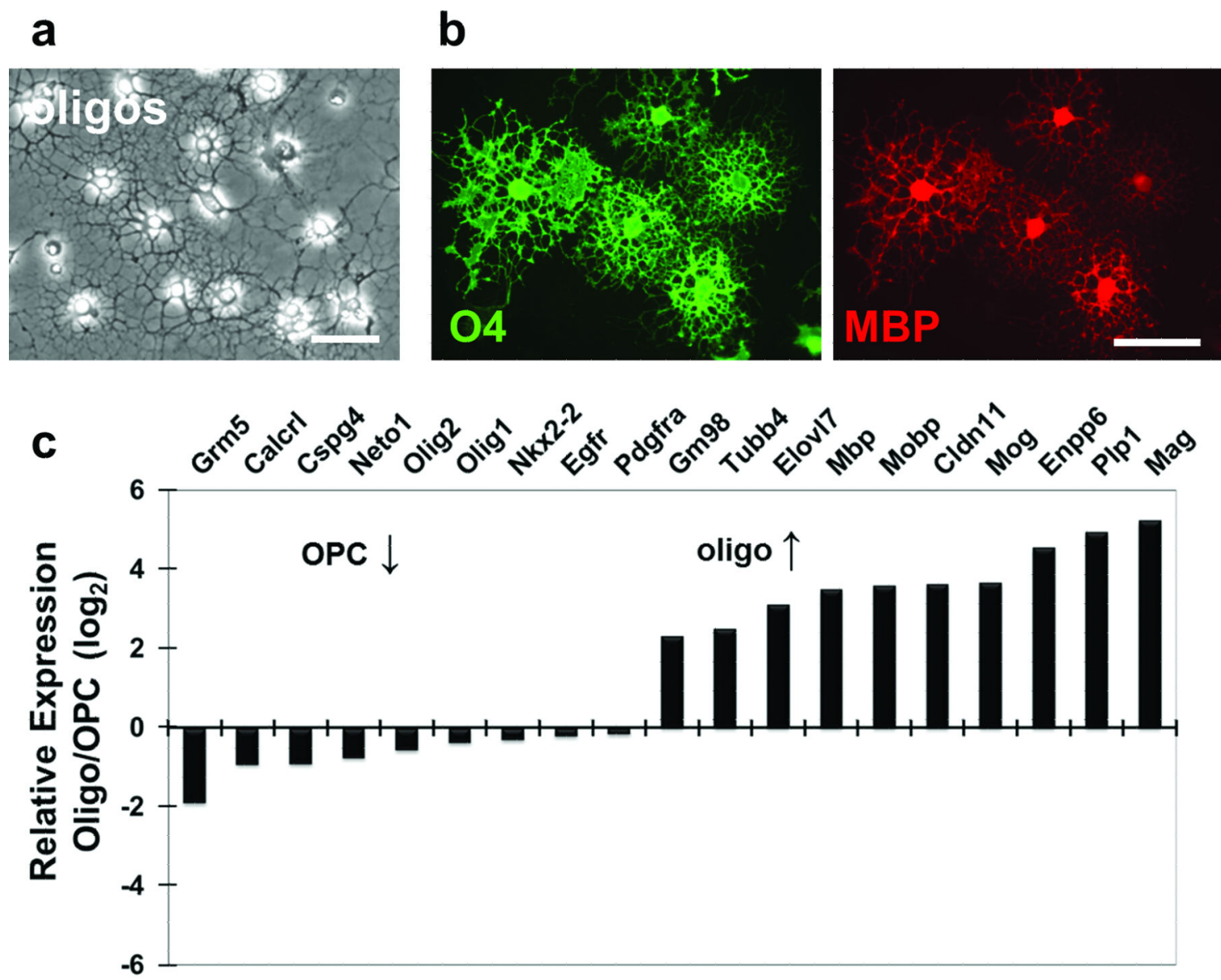

d
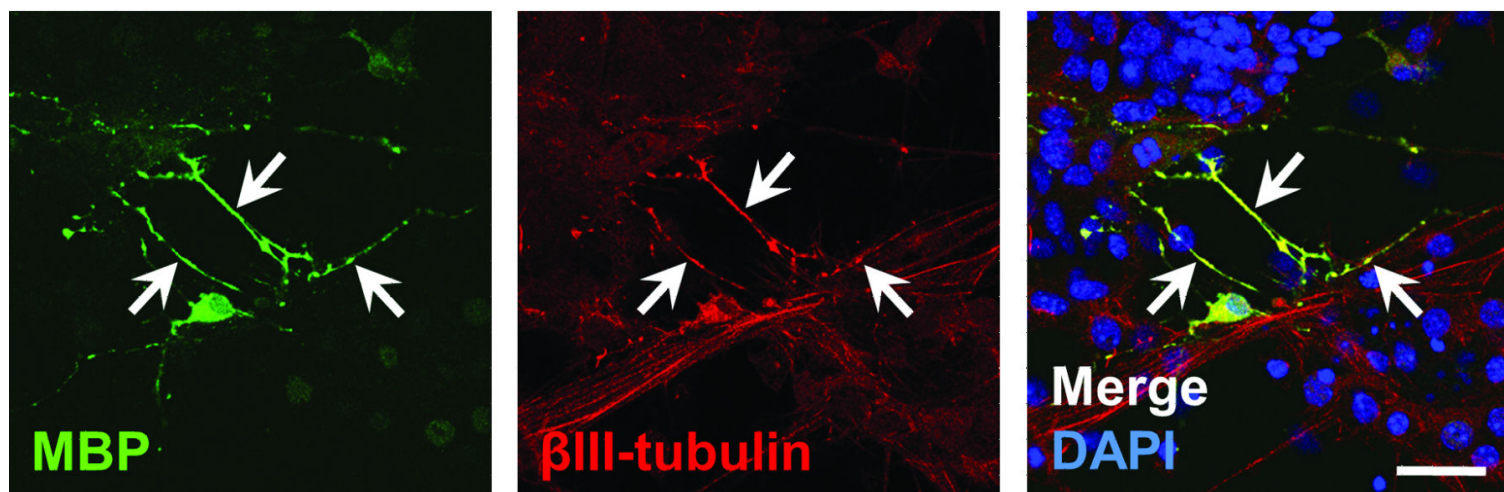

Figure 3. EpiSC-derived OPCs differentiate into oligodendrocytes in vitro

(a-b) EpiSC-derived OPCs cultured in differentiation-inducing media for three days (a) adopt a mature oligodendrocyte ('oligo') morphology by phase contrast and (b) co-express $\mathrm{O} 4$ (green) and MBP (red). (c) Genome wide transcriptional profiling during the transition of EpiSC-derived OPCs to oligodendrocytes revealed a rapid down-regulation of OPCspecific genes and up-regulation of genes specific to oligodendrocytes. (d) EpiSC-derived OPCs seeded on in vitro cultured embryonic mouse cortical neurons showed (see arrows) 
extension of $\mathrm{MBP}+$ (green) processes along the $\beta \mathrm{III}-$ tubulin+ (red) nerve axons, with DAPI (blue). Scale bars, $50 \mu \mathrm{m}$. 
a

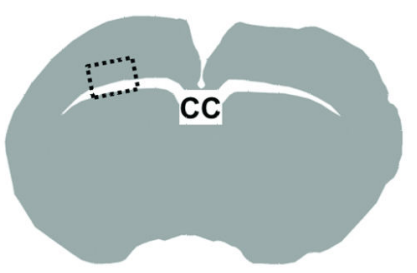

b

EpisC-OPC

injection

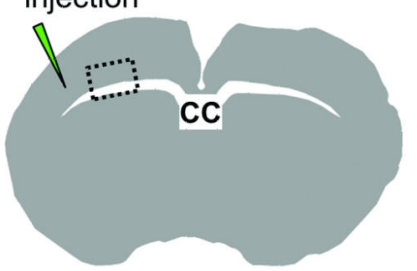

Wild type control slice

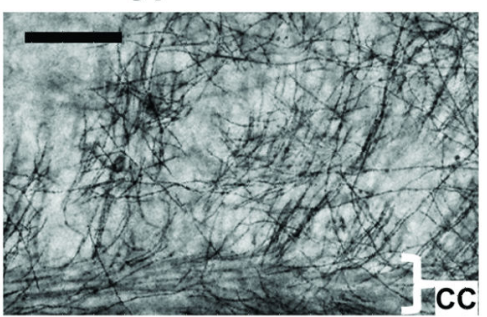

\section{EpiSC-OPC (p4)} injected $M b p^{\text {shi/shi }}$ slice

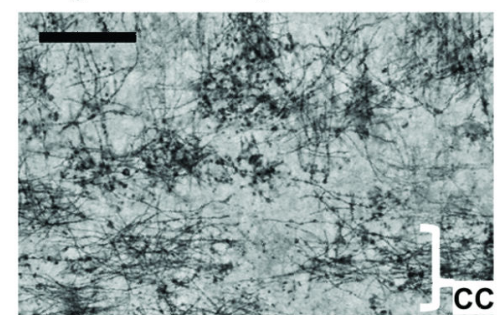

$M b p^{\text {shi/shi }}$ slice

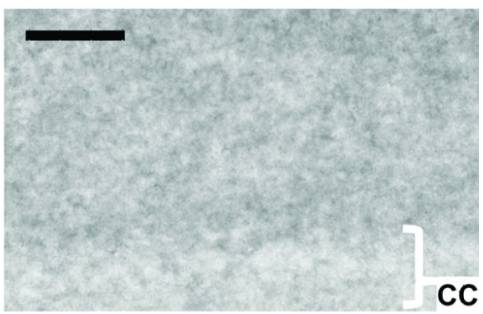

EpiSC-OPC (p10) injected $M b p^{\text {shi/shi }}$ slice

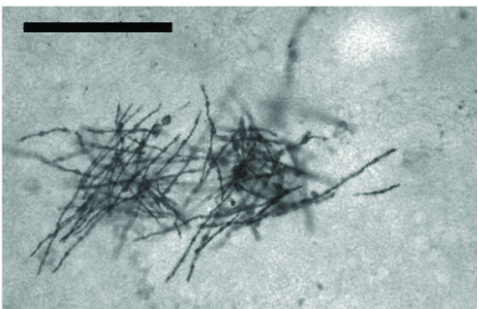

C

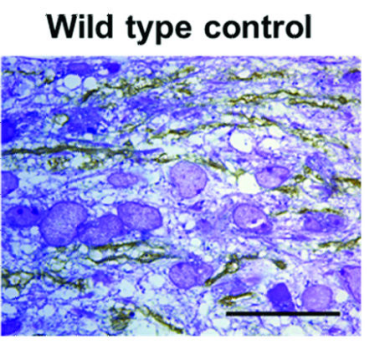

EpiSC-OPC injected Mbp ${ }^{\text {shi/shi }}$ slice

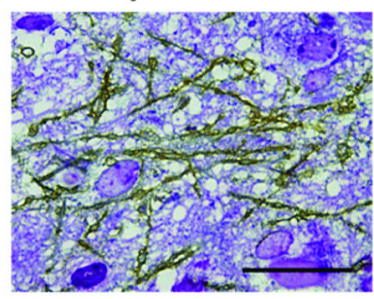

EpiSC-OPC injected $M^{\text {Mbphi/shi }}$ slice

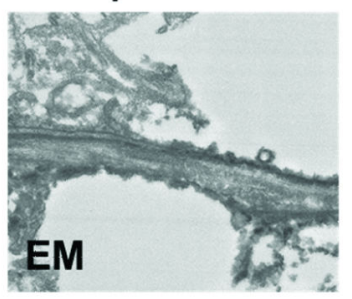
$M b p^{\text {shi/shi }}$ slice

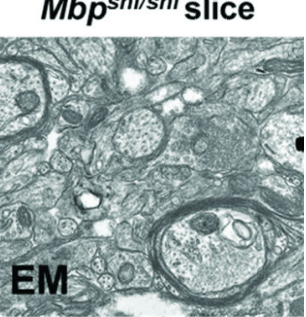

\section{d
EpiSC-OPC injected Mbpshi/shi brain

\section{corpus callosum}

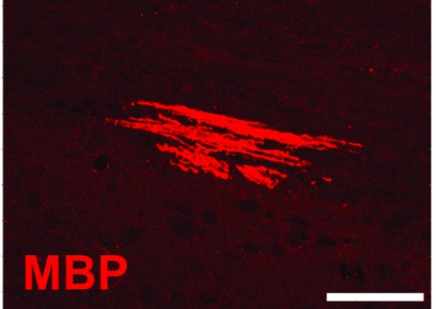

\section{EpiSC-OPC injected $M_{b p}{ }^{\text {shi/shi }}$ brain}

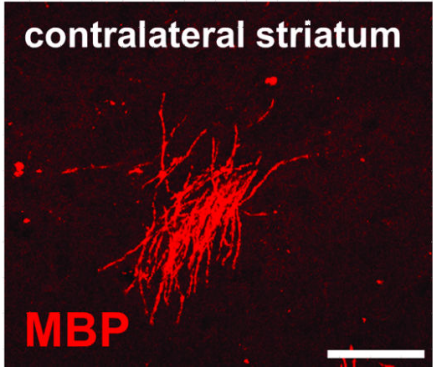

Figure 4. EpiSC-derived OPCs are myelinogenic

(a) Coronal sections of early postnatal (P2-4) mouse forebrain cultured for 13 days show extensive MBP+ (black) segments in sections from wild type mice and the complete lack of $\mathrm{MBP}+$ (black) segments in shiverer $\left(\mathrm{Mb}^{\text {shi/shi }}\right)$ mutants (lethally hypomyelinated due to lack of $M b p$ ). Images were taken within the region outlined by the dotted box. (b) Injection of EpiSC-derived OPCs into shiverer forebrain sections reveal extensive MBP+ (black) myelin sheaths after 10 days. No differences were noted in the myelinogenic capacity of low passage (p4) and high passage (p10) EpiSC-derived OPCs. (c) Toluidine blue stained 
sections $(1 \mu \mathrm{m})$ as well as electron microscopic (EM) analysis showed that EpiSC-derived OPCs produce compact myelin. (d) Injection of EpiSC-derived OPCs into early post-natal shiverer mutant mice reveals clear myelination both in the corpus callosum as well as the contralateral striatum (day 21 after injection). $\mathrm{CC}=$ corpus callosum. Scale bars, $100 \mu \mathrm{m}$ (a,b), $25 \mu \mathrm{m}(\mathbf{c})$, and $50 \mu \mathrm{m}(\mathbf{d})$. 
a

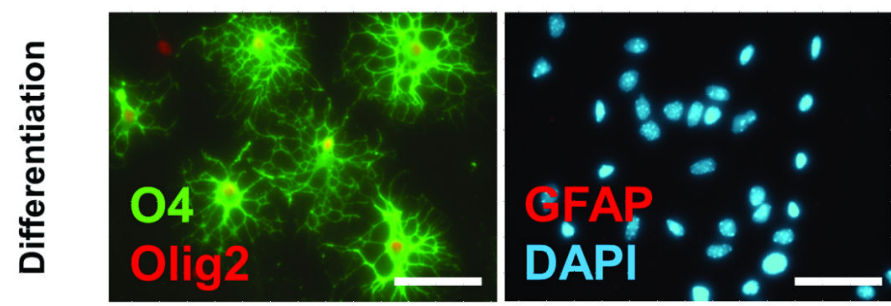

b
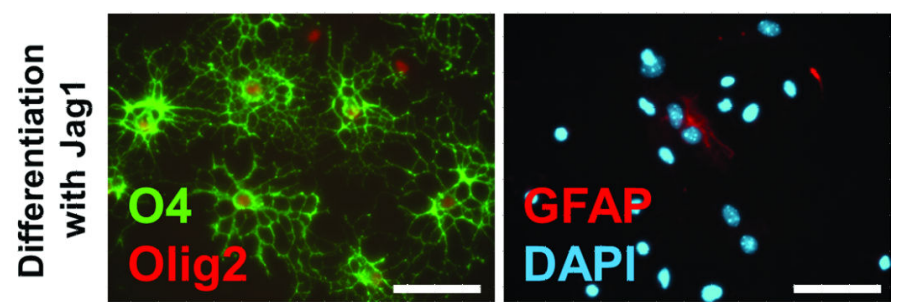

C
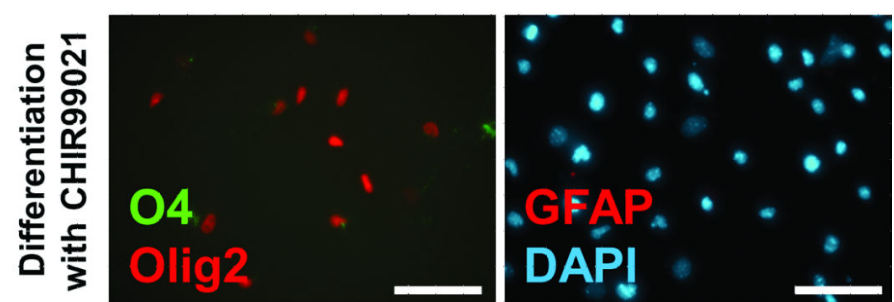

d
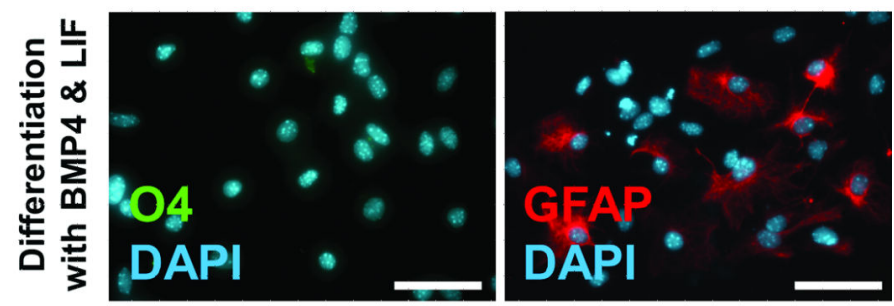

e

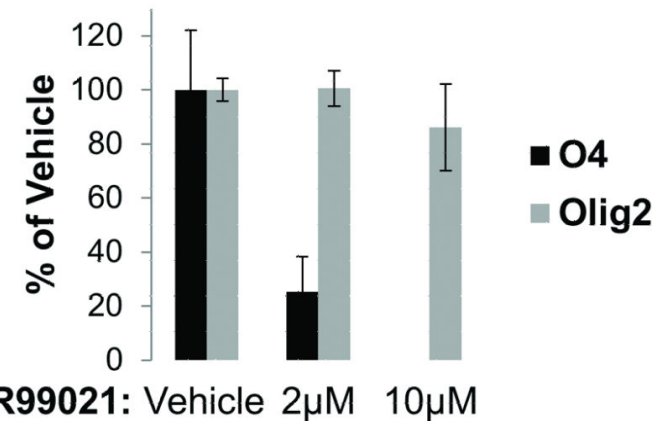

Figure 5. Screening for extrinsic signals that regulate the fate of EpiSC-derived OPCs (a) Stimulation of EpiSC-derived OPCs (Olig2+ and O4-negative) with a cocktail of defined factors results in their robust differentiation into Olig2+ and O4+ oligodendrocytes in 2 days. (b) Activation of the Notch pathway (with Jag1) signaling cascade during differentiation does not drastically alter the normal transition of OPCs to oligodendrocytes. (c) Inhibition of GSK3 $\beta$ (with CHIR99021), a negative regulator of the canonical Wnt/ $\beta$ catenin signaling pathway, blocks the transition of OPCs into oligodendrocytes. (d) Stimulation with BMP4 and LIF results in the respecification of OPCs into GFAP+ 
astrocytes. (e) Quantification of the effect of GSK3 $\beta$ inhibition using CHIR99021 to block the differentiation of OPCs into O4+ oligodendrocytes $\left(>2.4 \times 10^{3}\right.$ cells were manually scored from random fields of triplicate wells from two independent experiments and shown $+/-$ s.d.). Scale bars, $50 \mu \mathrm{m}$. 